\title{
Minocycline Hydrochloride Entrapped Biomimetic Nanofibrous Substitutes for Adipose-Derived Stem Cells Differentiation into Osteogenesis
}

\author{
Praveena Jayaraman $^{1}$ - Chinnasamy Gandhimathi ${ }^{1}$ - Jayarama Reddy Venugopal ${ }^{2}$. \\ Seeram Ramakrishna ${ }^{2}$ - Dinesh Kumar Srinivasan ${ }^{1}$ (D)
}

Received: 2 November 2015 / Accepted: 25 January 2016 /Published online: 12 February 2016

(C) The Regenerative Engineering Society 2016

\begin{abstract}
Hybrid biocomposite nanofibrous structures that mimics native extracellular matrix have been extensively applied for bone tissue engineering (BTE) due to their potential in efficiently inducing cellular response for the secretion of extracellular matrix (ECM). This study performed fabrication of uniform porous polycaprolactone (PCL), polycaprolactone/ silk fibroin (PCL/SF), polycaprolactone/silk fibroin/ minocycline hydrochloride (PCL/SF/MH), polycaprolactone/ collagen (PCL/COL), and polycaprolactone/collagen/ minocycline hydrochloride (PCL/COL/MH) biocomposites nanofibrous scaffolds by electrospinning, for comparing their properties to use in bone tissue regeneration. Field emission scanning electron microscopy (FESEM) images of fabricated nanofibrous scaffolds revealed porous, beadless, uniform fibers of diameter in the range of $147.13 \pm 28.02$ to 176.53 $\pm 22.34 \mathrm{~nm}$ and porosity around $82-93 \%$. Adipose-derived stem cells (ADSCs) considered as the novel cell therapeutics were cultured on these electrospun fibrous scaffolds to undergo osteogenic differentiation for BTE. The cell morphology, proliferation, and interactions were analyzed by CMFDA dye extrusion, MTS assay, and FESEM analysis, respectively. Differentiation of ADSCs into osteogenesis was determined by alkaline phosphatase activity, mineralization by alizarin red
\end{abstract}

Dinesh Kumar Srinivasan

dineshkumar@ntu.edu.sg

1 Cellular and Molecular Epigenetics Lab, Lee Kong Chian School of Medicine, Nanyang Technological University, Singapore, Singapore

2 Center for Nanofibers and Nanotechnology, Nanoscience and Nanotechnology Initiative, National University of Singapore, Singapore, Singapore staining, and osteogenic protein expression by immunofluorescence analysis. The results demonstrated that the addition of SF and MH to PCL-based scaffolds improved the mechanical stability, interconnected pores, and surface roughness of the scaffolds initiating heightened biological functions such as ADSCs adhesion, proliferation, differentiation, and mineralization into osteogenesis for bone tissue regeneration.

\section{Lay Summary}

Globally, the rate of bone defects or trauma has been trending upwards and is predicted to rapidly increase by 2020 . This is mainly due to the lack of physical activity, age, and increased obese populations. A basic understanding of the morphological characteristics and biological functions of mineralized bone tissue substrates is required for effective clinical treatments. The engineered bone tissue substrates have been potentially used as an alternative to the traditional bone grafts. However using these engineered bone substrates in clinical practices has certain limitations. These limitations can be overcome by the inclusion of natural polymers, growth factors, and stem cells. The current study demonstrates the addition of silk fibroin and minocycline hydrochloride to polycaprolactone-based scaffolds potentially enhanced adipose-derived stem cells differentiation into osteogenesis.

Keywords Polycaprolactone - Silk fibroin · Collagen · Minocycline hydrochloride $\cdot$ Mineralization $\cdot$ Differentiation · Bone tissue engineering

\section{Introduction}

Bone defects produced by trauma or osteoporosis lead to enormous therapeutic challenges in orthopedics and surgery due to the loss of blood and injury of nerves and blood vessels. Bone 
is a complex tissue which contains two major components such as nanohydroxyapatite $(70 \%)$ and collagen $(30 \%)$ by weight along with the elementary component water. The water content in bone is specific to each species and varies depending on the age of species [13, 42]. The major functions of the bone are to provide the mechanical strength and structural framework, maintain the calcium and phosphorus content in the metabolic process, and improve the blood $\mathrm{pH}$ regulation [39]. Various other conventional therapies applied to repair these bone damages include autograft, allograft, and xenograft. Even though these techniques substantially prevent the patient's death, they suffer due to serious limitations [8]. In autograft, there is an increased risk for infection and inadequate availability, whereas in xenografts, patient undergoes a permanent immunosuppression treatment with transmitted viral disease, infection, tumor development, and many side effects $[17,20]$. Direct grafting of allogeneic donor tissue faces many problems such as pathogen transmission and insufficient or rejection of donor organs [28].

Autogenic tissue grafting addresses most of the limitations and reduces the pathogenic transmission, rejection, and dependency for donor tissues. Hence, the construction of tissue-engineered scaffold replacements in vitro is known to be a suitable alternative for direct transplantation of tissues or organs. These tissue-engineered scaffolds tend to regenerate or restore the defected or damaged bone tissues $[8,10,46]$. The inclusion of biomolecules into polymeric scaffolds improves its mechanical strength, pore geometry and surface roughness, and thus meets the requirement of a bone substitutes. These bone substitutes allows the cells to infiltrate, adhere, integrate, and proliferate in the wounded region of the bone. However, this is not always successful due to their lack of flexibility and significant thickness of the samples [30]. Therefore, it is important to fabricate these scaffolds with significant properties that can improve natural healing process, delivery of cells or molecules to the wound area, flexibility, and well organized overall structure of the scaffolds. To aid bone tissue regeneration, natural or synthetic polymers are specifically engineered and these substitutes influence the capability of cells to adhere to the surface, to grow and function [9]. Several methods used for fabricating biocomposite scaffolds include melt-spinning, wet-spinning, extrusion molding, and electrospinning. Electrospinning is the most predominant method as it can generate materials with nanoscale levels and provide abilities to modify the nanofibers composition and porosity for its desired applications. This method even offers greater surface area to volume ratio of the nanofibrous scaffolds [40]. The functionalized polymeric scaffolds made from different materials (natural or synthetic) have been investigated for its application in tissue regeneration [18]. Biodegradable synthetic polymer polycaprolactone (PCL) nanofibrous scaffolds are extensively used for wound healing due to their inherent properties such as mechanical stability, porosity, excellent oxygen permeability, controlled water loss, and improved fluid drainage ability [19, 25, 34, 44].

Collagen (COL) is a natural protein that provides enhanced cell adhesion and proliferation to form tissues [32]. Biodegradable PCL is significantly used for replacing the damaged bone tissue by blending with collagen to enhance cell adhesion, interaction, and proliferation on the desired sites. These scaffolds have $90 \%$ porosity along with the interconnected pores for cell adhesion and migrate to form the required bone substitutes $[15,36]$. Silk fibroin $(\mathrm{SF})$ is a naturally occurring insoluble protein obtained from silkworm (larvae of Bombyx mori) that consists of two main proteins such as sericin and fibroin. The advantages of fibroin such as mechanical stability, slow degradability, ease of process ability, and biocompatibility created its focus towards biomedical applications. SF-based scaffold had improved the cell adhesion and proliferation of osteoblast, and also mimics the natural extracellular matrix (ECM) [5, 7, 11, 12, 16, 21, 29, 45]. Minocycline hydrochloride $(\mathrm{MH})$ is a derivative of tetracycline, broad-spectrum antibiotic and an effective antiinflammatory drug that has been widely used to treat any infectious diseases $[4,33]$.

Stem cells cultured on the fabricated biocomposites scaffold has been a suitable option for enhancing wound healing kinetics, angiogenesis, collagen deposition, granulation tissue formation, and biocompatibility. SF-based biocomposites have good elasticity, biocompatibility, slow degradability, and controlled surface roughness enhancing cell proliferation, interaction, and migration. These features reestablish the functionality of damaged bones and mimic the natural ECM by providing an ideal environment for cell attachment and proliferation. COL-based scaffolds are biocompatible and biologically active key components in bone tissue regeneration. However, the mechanical properties of COL-based scaffolds are inadequate and its porous structure varies in wet-state. Adipose-derived stem cells (ADSCs) are easily obtained by isolating from the liposuction materials without any ethical problem [35]. The in vitro studies have shown that these cells had a stable growth, proliferation, and even capable of differentiating into lineages for bone, cartilage, and skin [38, 49]. Several growth factors such as bone morphogenetic protein, vascular endothelial growth factor, fibroblast growth factor, and insulin-like growth factor have the influence on osteoblast behavior and hence they are widely used in bone tissue formation. Yun et al. reviewed the in vitro and in vivo performance of these growth factors in the repair and restoration of bone tissues [47]. Our hypothesis is to fabricate hybrid biocomposite nanofibrous scaffolds of COL and/or SF blended with PCL and MH that mimics the native ECM for bone tissue engineering. The present study cultured ADSCs on PCL/SF/MH biocomposite nanofibrous scaffolds, suitable in terms of cell adhesion, proliferation, and further osteogenic differentiation and mineralization for bone tissue regeneration. 


\section{Material Methods}

\section{Materials}

ADSCs were obtained from Lonza (Portsmouth, NH). Fetal bovine serum (FBS), Dulbecco's modified eagle's medium (DMEM), penicillin-streptomycin solution, PCL (Mw 80, 000), 1,1,1,3,3,3-hexafluor-2-propanol (HFP), and minocycline hydrochloride were procured from SigmaAldrich, Singapore. Collagen type I was purchased from Koken Co, Tokyo (Japan) and silk fibroin purchased from Zhang Peng International trading Ltd, Singapore.

\section{Fabrication of Nanofibrous Scaffolds}

PCL $10 \%(w / v)$, PCL/SF $(8 \% / 2 \%)(w / v)$, PCL/SF/MH $(7.5 \% / 2 \% / 0.5 \%)(w / v)$, PCL/COL $(8 \% / 2 \%)(w / v)$, and PCL/COL/MH $(7.5 \% / 2 \% / 0.5 \%)(w / v)$ were prepared by dissolving in HFP at the concentration of $10 \%$ solutions. The polymer solutions were kept for stirring overnight at room temperature to ensure homogeneity, then it was loaded into a syringe $(3 \mathrm{ml})$ which is attached to the blunted $25 \mathrm{G}$ $(0.5 \mathrm{~mm} \times 25 \mathrm{~mm})$ stainless steel needle via syringe pump (KD Scientific Inc., MA, USA) at a constant flow rate of $0.8 \mathrm{ml} / \mathrm{h}$ which was fixed in order to generate uniform fibers. Using a high voltage power supply (Gamma High Voltage Research, Florida, USA), a 15-kV high voltage was applied to draw the homogenized polymeric solution into fibers from the spinneret to the collector plate wrapped with aluminium foil. The distance between the needle tip and collector plate was maintained at $12.5 \mathrm{~cm}$ throughout the process. The electrospun nanofibers were collected on $15 \mathrm{~mm}$ coverslips which were placed on the surface of the aluminium foil. Later, the coverslips were separated from the foil and collected in a petri dish using forceps. These coverslips were then allowed to dry overnight under vacuum oven for cell culture studies.

\section{Characterization of Electrospun Nanofibrous Scaffolds}

The surface morphology of fabricated biocomposite nanofibrous scaffolds was observed using field emission scanning electron microscope (FESEM JEOL JSM-5600LV) by an applied voltage of $15 \mathrm{kV}$, after coating the scaffolds with $5 \mathrm{~nm}$ thickness of platinum (JEOL JFC-1200 fine coater, Japan). The fiber diameter of the scaffolds was measured from the FESEM images, and their average and standard deviation (SD) of the selected fibers were calculated by image analysis software (ImageJ, National Institutes of Health, USA). The hydrophilic/hydrophobic nature of fabricated nanofibers was studied through sessile drop water contact angle measurement using VCA Optima Surface Analysis system (AST products, Billerica, MA). The plasma cleaner with electrodeless radio frequency radiance discharge (PDC-001, Harrick Scientific
Corporation, USA) was used to plasma treat the highly hydrophobic PCL scaffolds for about 2 min under vacuum, by applying a power of $30 \mathrm{~W}$. The mechanical strength of fabricated nanofibrous scaffolds was measured via table top tensile tester (Instron 3345, USA) at a crosshead speed of $10 \mathrm{~mm} \mathrm{~min}^{-1}$. The test samples were cut in a rectangular dimension of $10 \mathrm{~mm} \times 20 \mathrm{~mm}$ from the electrospun nanofibrous scaffolds. These samples were placed vertically onto the gripping unit and a load of $10 \mathrm{~N}$ was applied for obtaining the stress-strain curve of the scaffolds. The elastic modulus, tensile strain, and stress of the scaffolds were determined based on the attained stress-strain curves. The pore size and porosity of the nanofibrous scaffold were examined by capillary flow porosimeter (Porous Materials Inc, USA).

\section{Cell Culture}

ADSCs were cultured in DMEM added with $10 \%$ FBS and $1 \%$ of antibiotic and antimycotic agents in a $75 \mathrm{~cm}^{2}$ flask. Then it was incubated at $37{ }^{\circ} \mathrm{C}$ for 5 days in a humidified condition consisting of $5 \% \mathrm{CO}_{2}$. The cell culture medium was changed every 2 days. The electrospun nanofibers collected on $15 \mathrm{~mm}$ coverslips were placed in a sterilized 24-well plate along with the stainless steel rings in order to prevent lifting of fibrous scaffolds. The biocomposite scaffolds and the tissue culture polystyrene (TCP) as the control coverslips were sterilized in ultraviolet light for about 2-3 h; later the samples were washed with phosphate-buffered solution (PBS) three times every $15 \mathrm{~min}$ in order to remove residual solvents, and then the complete medium was added and kept overnight in the incubator before cell seeding. ADSCs grown at confluences were detached by trypsin, centrifuged, counted via trypan blue using hemocytometer, and finally seeded onto the nanofibrous scaffolds with a density of 9000 cells per well and incubated at suitable conditions for the cell growth, differentiation, and mineralization.

\section{Cell Proliferation}

The proliferation of cells on the fabricated biocomposite scaffolds and TCP (control) were measured by colorimetric MTS assay using CellTiter 96 Aqueous One solution (Promega, Madison, WI). After the 5th, 10th, and 15 th day of cell culture, the medium from the well plate was removed and the nanofibrous scaffolds were rinsed with PBS to remove any unattached or dead cells and then incubated in a serum-free DMEM with $20 \%$ MTS reagent at $37{ }^{\circ} \mathrm{C}$ for $3 \mathrm{~h}$. After incubation, the solution was transferred to sterilized 96-well plate and the absorbance was measured at $490 \mathrm{~nm}$ using spectrophotometric plate reader (FLUOstar OPTIMA, BMG Lab Technologies, Germany). 


\section{Cell Morphology}

ADSCs morphology was observed after 15 days of cell culture onto the biocomposite scaffolds using FESEM. The media was removed from the well plates and $3 \%$ glutaraldehyde in PBS was used to fix the samples for about $3 \mathrm{~h}$. Then the scaffolds were washed using distilled water for about $15 \mathrm{~min}$ and subsequently dehydrated with various concentrations of ethanol such as $30,50,75,90$, and $100 \%(v / v)$. Consequently, the samples were immersed in $200 \mu \mathrm{l}$ of hexamethyl disilazane solution and allowed to dry under the fume hood overnight at room temperature. Later the samples were coated with platinum before analyzing the cell morphology using FESEM.

\section{Expression for CMFDA Dye}

CMFDA (5-chloromethylfluorescein diacetate) was used to study the fluorescent dye expression in the seeded ADSCs, which cleavages its acetate group through cytosolic esterases and forms a brightly fluorescent expression of CMFDA derivative. After 15 days of cell seeding, the culture medium was removed and the samples were immersed in $180 \mu \mathrm{l}$ serum-free medium and $25 \mu \mathrm{l}$ CMFDA $(25 \mu \mathrm{M})$ followed by $2 \mathrm{~h}$ of incubation at $37^{\circ} \mathrm{C}$. The CMFDA medium was changed with complete medium and the samples were incubated overnight in $5 \% \mathrm{CO}_{2}$. Later the complete medium from the well plate was removed and rinsed with PBS followed by serum-free medium and the cells were observed using inverted Leica DM IRB laser scanning microscope (Leica DC 300F) at $488 \mathrm{~nm}$.

\section{Alkaline Phosphatase Activity}

The differentiation of ADSCs into osteogenic lineage was determined by alkaline phosphatase (ALP) activity. Alkaline yellow liquid substrate for ELISA (Sigma Life Sciences, USA) was used to measure the ALP activity. The ADSCs cultured scaffolds for a period of 5, 10, and 15 days were washed twice with PBS followed by the addition of $400 \mu 1$ PNPP to each scaffold and kept in the incubator for $30 \mathrm{~min}$ till the solution color turned yellow. Then, the samples were added with $200 \mu \mathrm{l}$ of $2 \mathrm{~N} \mathrm{NaOH}$ solution and finally transferred to the 96 well-plates for measuring the absorbance in a microplate reader at $405 \mathrm{~nm}$.

\section{Mineralization of ADSCs}

The osteogenic differentiation and mineralization of cells were studied and quantified using Alizarin red-S (ARS) staining. On day 15, the electrospun scaffolds seeded with ADSCs were washed with PBS thrice and then fixed with $70 \%$ ice cold ethanol for $1 \mathrm{~h}$. These composites were washed with distilled water thrice and stained using ARS $(40 \mathrm{mM})$ for $20 \mathrm{~min}$. Subsequently washing with distilled water, the scaffolds were observed using inverted optical microscope and the images were taken with inverted Leica DM IRB microscope (Leica DC 300F) and then the stain was eluted with use of $10 \%$ cetylpyridinium chloride for $1 \mathrm{~h}$. The dye was collected and the absorbance was read at $540 \mathrm{~nm}$ in a spectrophotometer (Thermo Spectronics, Waltham, MA, USA).

\section{Expression of Osteocalcin}

Differentiation of ADSCs into osteogenesis was demonstrated by immunofluorescence analysis by using both ADSC specific marker protein CD105 and osteoblast specific marker protein osteocalcin. The cells were initially fixed with para formaldehyde, washed with PBS, and then $100 \mu 1$ of $0.1 \%$ Triton $\mathrm{X}-100$ was added and incubated for $3 \mathrm{~min}$ in order to permeabilize the cell membrane. Subsequently, the nonspecific sites were blocked by incubating the samples in $3 \%$ BSA (Sigma) for $1 \mathrm{~h}$. Later, ADSC specific marker protein CD105 (Abcam, USA), a primary antibody, was added and incubated at a dilution of 1:100 for $90 \mathrm{~min}$ at room temperature and then washed with PBS. The Alexa Fluor 488 (Invitrogen-Green), a secondary antibody, was added to the samples at a dilution of 1:250 for $60 \mathrm{~min}$. The excess staining in the samples were washed with PBS three times every $15 \mathrm{~min}$; consecutively, osteoblast specific marker protein known as osteocalcin was added to the cells containing scaffold at a dilution of 1:100 for $1 \mathrm{~h}$ at room temperature. Furthermore, Alexa Fluor 594, a secondary antibody, was added at a dilution of 1:250 for $1 \mathrm{~h}$. Finally to remove the excess staining, samples were rinsed with PBS thrice every 15 min and incubated with DAPI at a dilution of 1:5000 for $30 \mathrm{~min}$. The samples were fixed on a glass slide by Vectashield mounting medium and observed using fluorescent microscope (Olympus FV1000).

\section{Statistical Analysis}

Experiments were run for five times and the data presented were expressed as mean \pm standard deviation (SD). Statistical differences were determined using $t$ test and ANOVA. Difference was considered statistically significant at $P \leq 0.05$.

\section{Results and Discussion}

\section{Morphology and Characterization of Nanofibrous Scaffolds}

Biocomposite nanofibrous scaffolds are the favorable replacements for obtaining natural ECM to regenerate functionally organized bone tissues because the nanostructure offers a near 

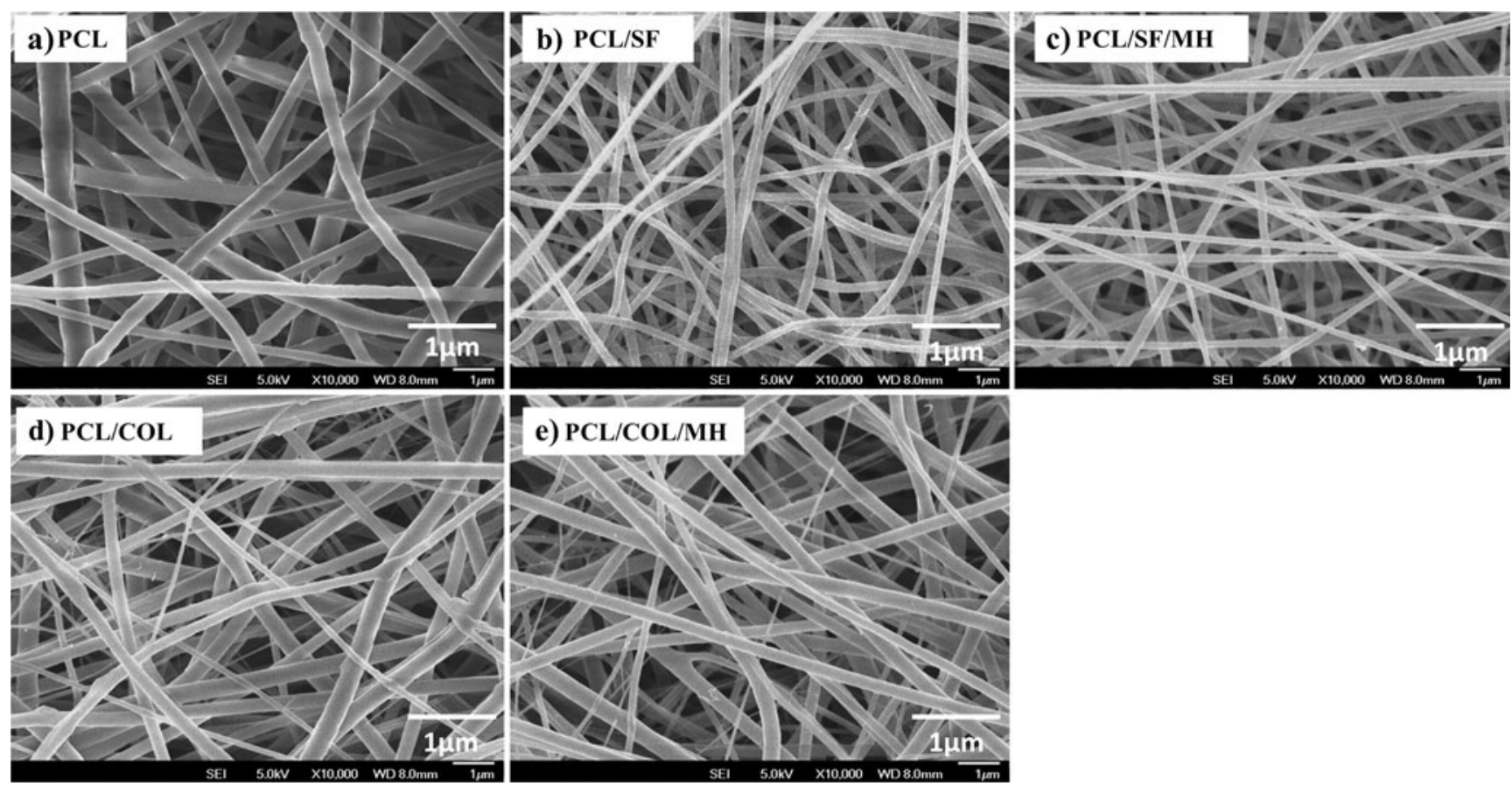

Fig. 1 FESEM images of the developed nanofibers: a PCL; b PCL/SF; $\mathbf{c}$ PCL/SF/MH; $\mathbf{d}$ PCL/COL; and e PCL/COL/MH (scale bar of $1 \mu \mathrm{m})$

approximation to native bone morphology. These nanofibrous scaffolds enhance the cell adhesion, proliferation, migration, and differentiation resulting in the formation of functional bone tissues [31]. The FESEM image of nanofibrous scaffolds exhibited uniform, beadless, porous nanofibrous structures (Fig. 1).

The water contact angle, fiber diameter, mechanical strength, and porosity of each electrospun nanofibrous scaffold was calculated and presented in the Table 1. The fiber diameter of electrospun nanofibers were obtained in the nanometer range of $147.13 \pm 28.02-176.53 \pm 22.34$ (Fig. 1). The PCL nanofibers were hydrophobic with the water contact angle of $129.2 \pm 6.4^{\circ}$. On incorporating protein biomolecules like silk fibroin and collagen, it exhibited hydrophilicity with the water contact angle of $50.43 \pm 11.1^{\circ}$ for PCL/SF, 66.18 $\pm 4.1^{\circ}$ for $\mathrm{PCL} / \mathrm{SF} / \mathrm{MH}, 31.79 \pm 8.4^{\circ}$ for $\mathrm{PCL} / \mathrm{COL}$, and $35.02 \pm 7.9^{\circ}$ for PCL/SF/MH scaffolds (Fig. 2). In order to stimulate tissue growth, the scaffold must have a large surface area and optimal pore size with interconnected pore network for cell adhesion and proliferation. The porosity and pore size of scaffolds were obtained between 82 to $93 \%$ and 1.05 and $1.7 \mu \mathrm{m}$ respectively, suggesting that the scaffolds are highly porous in morphology for the transportation of oxygen and nutrient in the scaffolds, its porosity should be $>90 \%$ [15].

The mechanical properties of PCL, PCL/SF, PCL/SF/MH, $\mathrm{PCL} / \mathrm{COL}$, and PCL/COL/MH nanofibrous scaffolds are shown in Table 1, and the scaffolds revealed a characteristic nonlinear stress-strain curve as shown in Fig. 3. The tensile strength obtained for PCL, PCL/SF, PCL/SF/MH, PCL/COL, and $\mathrm{PCL} / \mathrm{COL} / \mathrm{MH}$ nanofibrous scaffolds were $1.68,9.13$, 9.17, 8.49, and 7.87 MPa, respectively. The tensile properties of PCL/SH and PCL/SF/MH were higher than that of PCL, $\mathrm{PCL} / \mathrm{COL}$, and PCL/COL/MH nanofibers because the strength-to-density ratio of silk is up to ten times higher than that of steel [16]. The tensile break of electrospun biocomposite scaffolds revealed to be $148.08,144.18$, $133.92,148.25$, and $139.84 \%$, respectively. The results indicated (Table 1) that blending PCL with SF gives better

Table 1 Characterization of biocomposite nanofibrous scaffolds $(n=5)$

\begin{tabular}{lllllll}
\hline Nanofibrous scaffolds & Water contact angle $\left({ }^{\circ}\right)$ & Fiber diameter $(\mathrm{nm})$ & Pore size $(\mu \mathrm{m})$ & Porosity $(\%)$ & Tensile strength $(\mathrm{MPa})$ & Tensile break $(\%)$ \\
\hline $\mathrm{PCL}$ & $129.2 \pm 6.4$ & $147.13 \pm 28.02$ & $1.05 \pm 0.06$ & $87 \pm 5.2$ & $1.68 \pm 0.04$ & $148.08 \pm 3.95$ \\
$\mathrm{PCL} / \mathrm{SF}$ & $50.43 \pm 11.1$ & $176.53 \pm 22.34$ & $1.46 \pm 0.04$ & $90 \pm 5.7$ & $9.13 \pm 0.13$ & $144.18 \pm 1.82$ \\
$\mathrm{PCL} / \mathrm{SF} / \mathrm{MH}$ & $66.18 \pm 4.1$ & $160.64 \pm 17.48$ & $1.64 \pm 0.05$ & $92 \pm 4.1$ & $9.17 \pm 0.15$ & $133.92 \pm 4.62$ \\
$\mathrm{PCL} / \mathrm{COL}$ & $31.79 \pm 8.4$ & $172.31 \pm 21.44$ & $1.32 \pm 0.06$ & $93 \pm 2.22$ & $8.49 \pm 0.07$ & $148.25 \pm 2.25$ \\
$\mathrm{PCL} / \mathrm{COL} / \mathrm{MH}$ & $34.79 \pm 7.9$ & $173.83 \pm 15.45$ & $1.43 \pm 0.07$ & $82 \pm 3.02$ & $7.87 \pm 0.06$ & $139.84 \pm 3.84$ \\
\hline
\end{tabular}



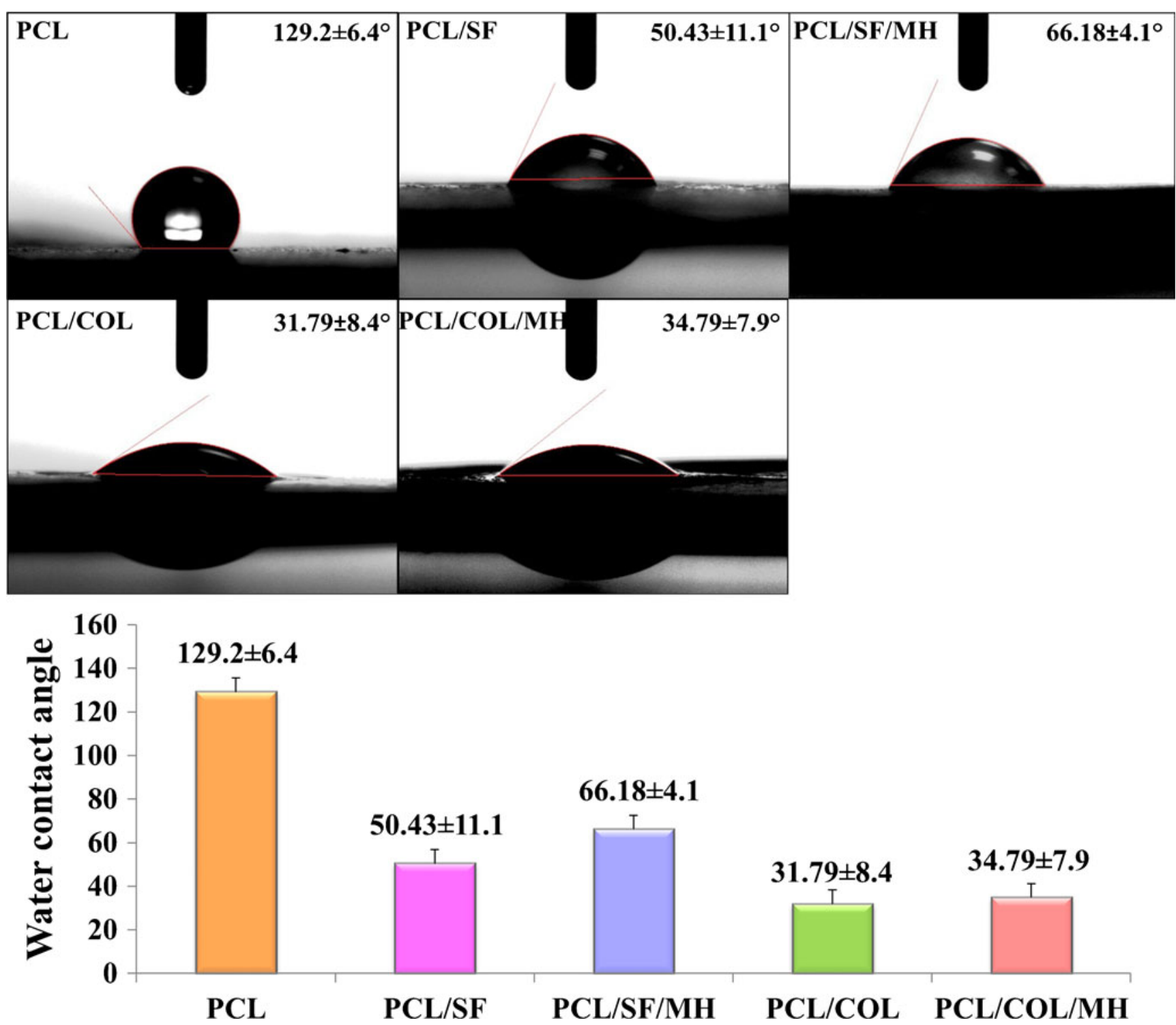

Fig. 2 Contact angle values of PCL, PCL/SF, PCL/SF/MH, PCL/COL, and PCL/COL/MH nanofibrous scaffolds

Fig. 3 Stress-strain curves of PCL, PCL/SF, PCL/SF/MH, $\mathrm{PCL} / \mathrm{COL}$, and PCL/COL/MH nanofibers under tensile loading of $10 \mathrm{~N}$

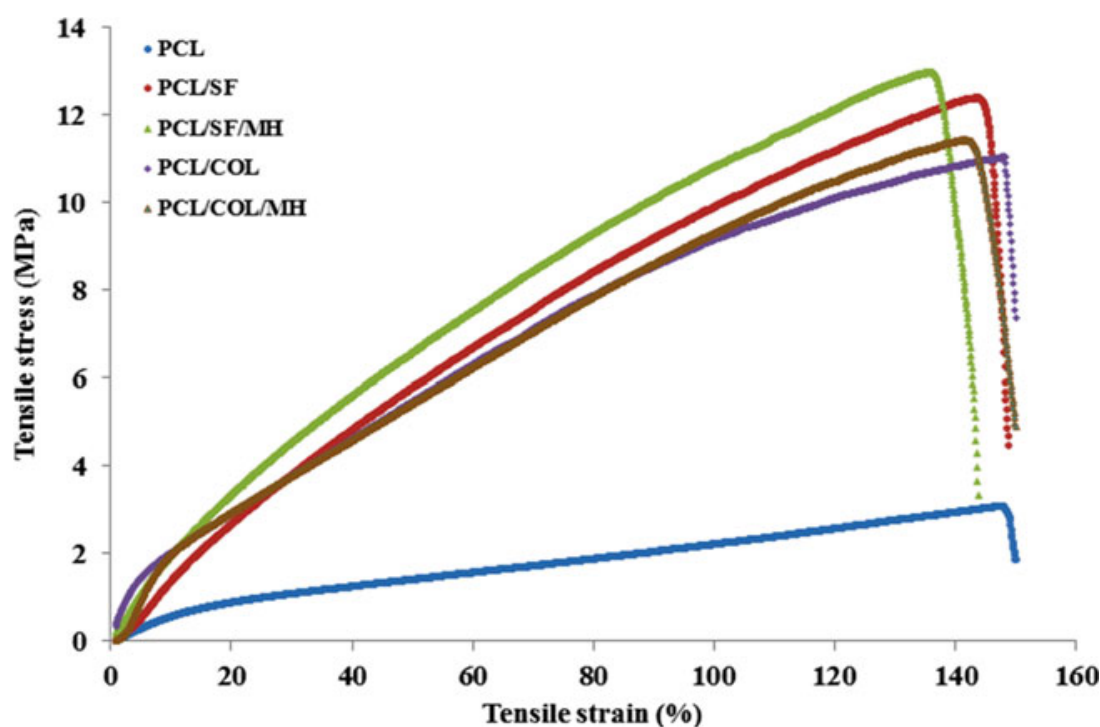


Fig. 4 ADSCs proliferation on biocomposites nanofibrous scaffolds. The error bar represents mean \pm standard deviation. Asterisks indicate statistical difference of proliferation as compared to PCL using $t$ test. Single asterisk indicates significant difference of $P \leq 0.05$

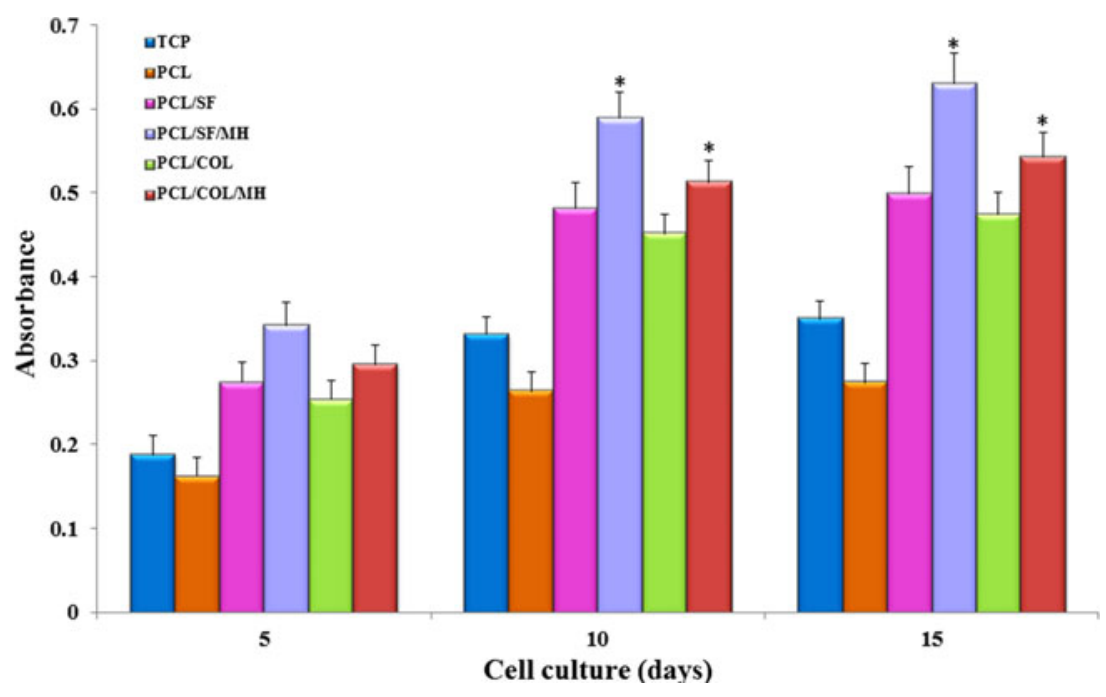

mechanical properties to the nanofibrous scaffolds. For tissue engineering applications, generally scaffolds have temporary mechanical support to withstand the stresses until new tissue formed. The results of tensile strength studies showed that the composite nanofibrous scaffold was highly desirable for penetrating cells inside the scaffolds for bone tissue regeneration. Mechanical stability of the scaffold plays a key role as the membrane should help cell growth and proliferation and degrade by itself as novel ECM starts regenerating to the damaged tissues.

\section{Cell Proliferation}

The subcellular interaction between cell and biocomposite material provides evidences for significant cell attachment, interaction, growth, and differentiation [27, 44]. The transition state of progenitor cells differentiation into osteogenic lineage is known by matrix maturation and consequent mineralization. Cell adhesion onto the ECM can be determined critically by its growth, interaction, migration, differentiation, and mineralization in the culture environment or living body. The initial attachment of
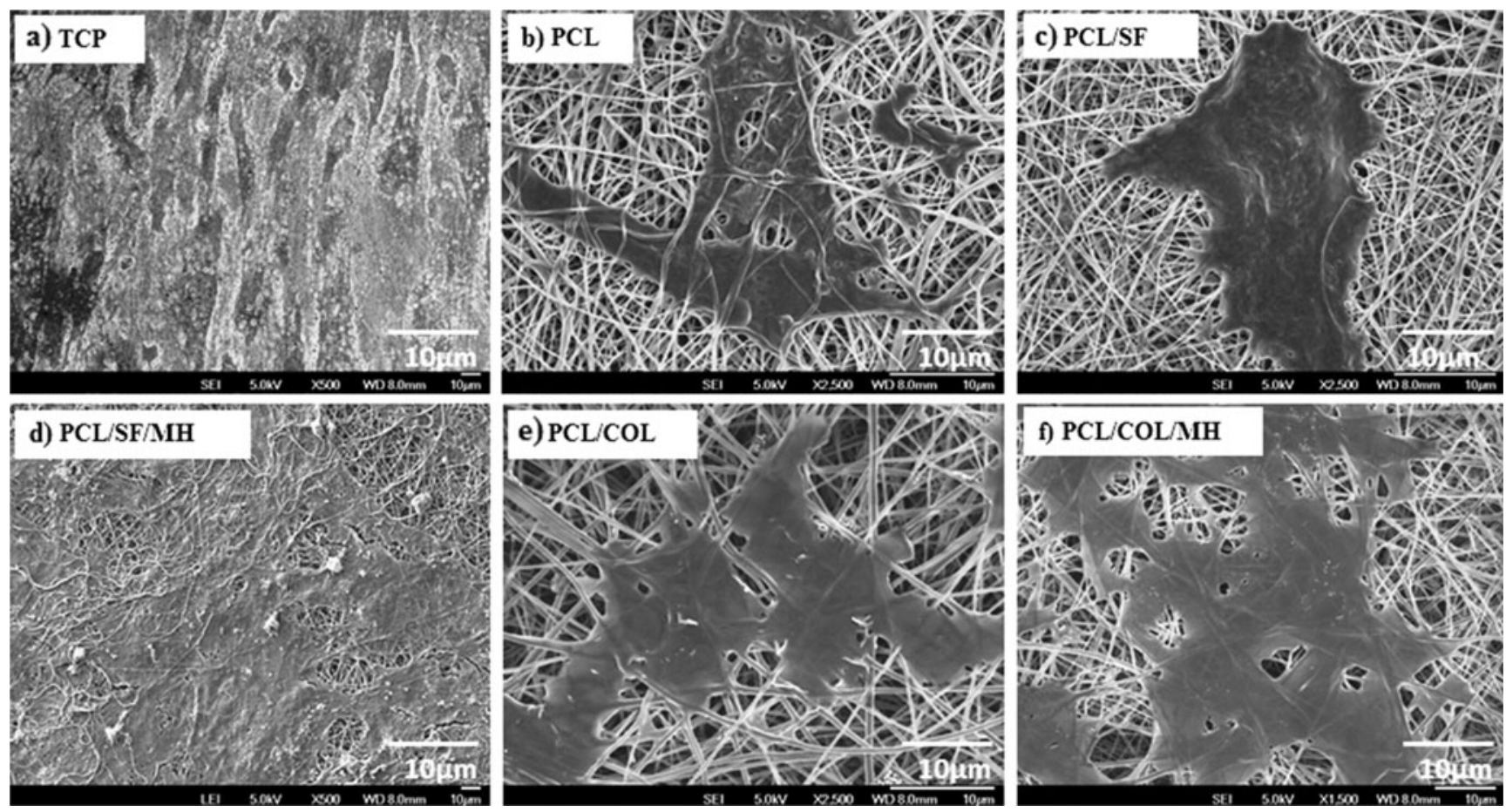

Fig. 5 FESEM images showing the cell-biomaterial interactions on a TCP; b PCL; $\mathbf{c}$ PCL/SF; d PCL/SF/MH; e PCL/COL; and f PCL/COL/MH nanofibrous scaffolds 

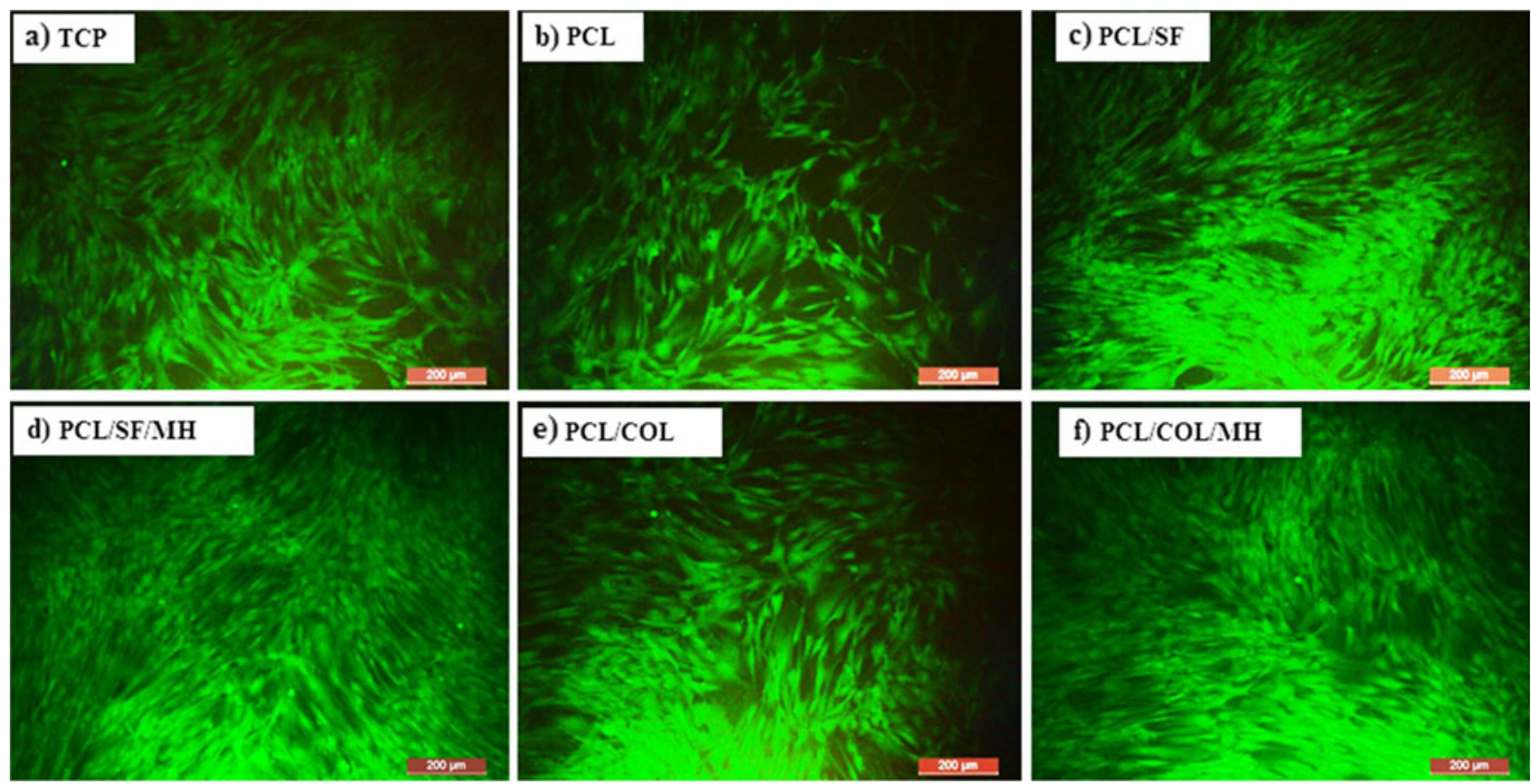

Fig. 6 CMFDA dye extrusion image to analyze the cell morphology on a TCP; b PCL; $\mathbf{c}$ PCL/SF; $\mathbf{d}$ PCL/SF/MH; e PCL/COL; and f PCL/COL/MH nanofibrous scaffolds at $\times 10$ magnifications

cells was mainly affected by the binding between adhesion molecules and the consequent mediation among cells and biocomposite material surface [2]. The proliferation of cells on nanofibrous scaffolds was defined by following their metabolism for a period of 15 days under specific absorbance at regular intervals. The proliferation of ADSCs was improved in PCL/SF biocomposites scaffold than PCL nanofibers and cell growth was increased from days 5 to 15 as shown in Fig. 4. The growth rate of ADSCs on electrospun PCL/SF/MH and PCL/COL/MH scaffolds increased significantly $(P \leq 0.05)$ when compared to PCL lacking of SF and COL for days 10 and 15. Additionally on day 15 of culture, $\mathrm{PCL} / \mathrm{SF} / \mathrm{MH}$ biocomposite scaffolds showed a statistical significance of $P \leq 0.05$ increased up to
$62 \%$ in cell growth when compared to PCL/COL/MH scaffold which increased up to $54.20 \%$ in cell growth on day 15 .

The biocomposites nanofibrous scaffolds were observed under FESEM, to measure its ability in improving the adhesion, interaction, growth, and alignment of cells. Figure 5 showed the ADSCs begin to adhere and stabilize themselves on the PCL/SF, PCL/SF/MH, PCL/COL, and PCL/COL/MH nanofibrous scaffolds for cell proliferation and differentiation into osteogenesis. The absence of SF, COL, and MH in the scaffold resulted in a random arrangement of cells on TCP and PCL. The PCL/SF/MH scaffolds exhibited the morphology of cells which are well attached and interconnected through intercellular connections. The intercellular connection formed
Fig. 7 Alkaline phosphatase activity showing the osteogenic differentiation of ADSCs on TCP, PCL, PCL/SF, PCL/SF/MH, $\mathrm{PCL} / \mathrm{COL}$, and PCL/COL/MH nanofibrous scaffolds on days 5 , 10 , and 15. Asterisk indicates significant difference of $P \leq 0.05$

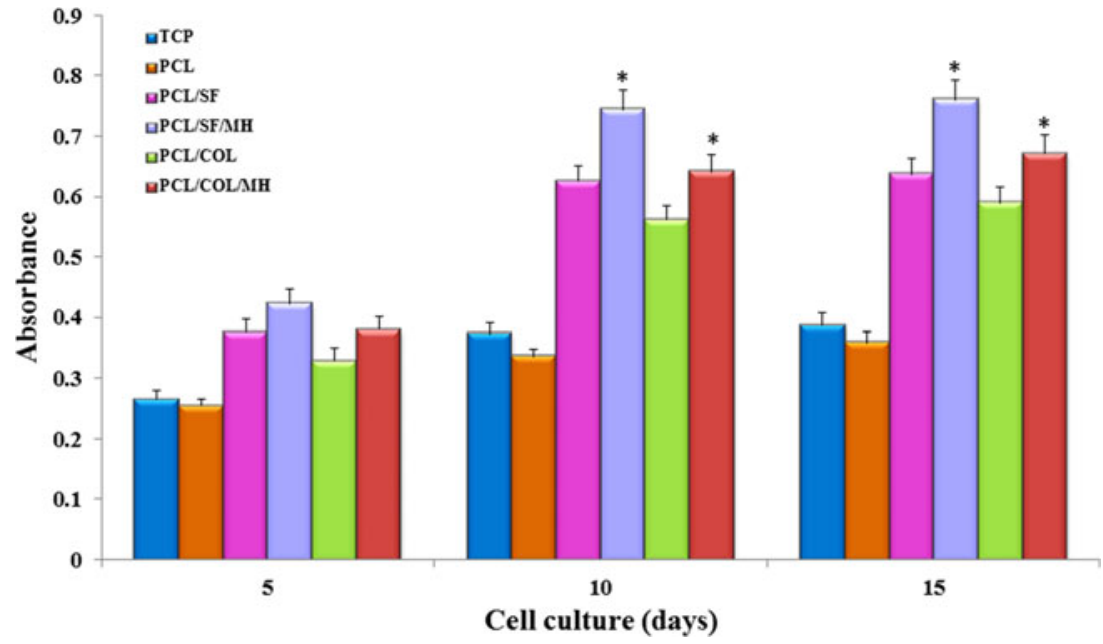



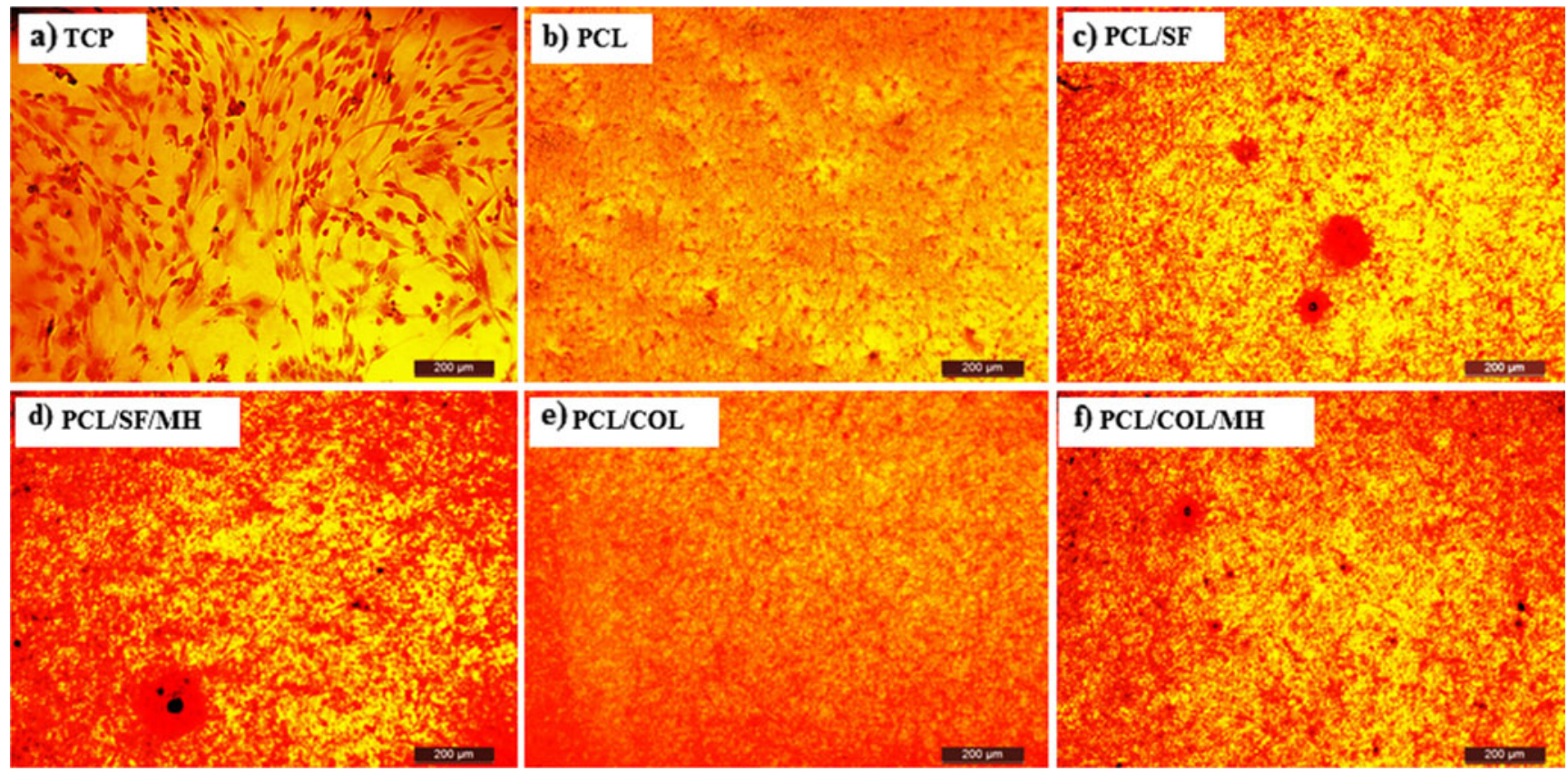

Fig. 8 Optical microscope images showing the mineralization of ADSCs using Alizarin red staining on day 15 (a-f) on a TCP; b PCL; $\mathbf{c}$ PCL/SF; d $\mathrm{PCL} / \mathrm{SF} / \mathrm{MH}$; e PCL/COL; and $\mathbf{f} \mathrm{PCL} / \mathrm{COL} / \mathrm{MH}$ nanofibrous scaffolds at $\times 10$ magnification

on PCL/SF/MH scaffolds was found to be superior compared to other biocomposite scaffolds. A porous biocomposite nanofibrous substitute engineered for tissue regeneration must have high porosity with large interconnected pores in order to improve proliferation and uniform distribution of cells by allowing the passage for oxygen and nutrients [22, 44]. When compared to PCL, PCL/SF, PCL/COL, and PCL/ $\mathrm{COL} / \mathrm{MH}$ composites, the porosity and pore size distribution of $\mathrm{PCL} / \mathrm{SF} / \mathrm{MH}$ were higher resulting in $92 \%$ and $1.64 \mu \mathrm{m}$, respectively. The PCL/SF/MH composite has a suitable morphology for better interaction and proliferation of cells. Cells are highly sensitive and interact to the topography and surface tension of the substrates [43].

The CMFDA analysis was done after the 15th day of culture which exhibited an increased amount of live cells on the
$\mathrm{PCL} / \mathrm{SF} / \mathrm{MH}$ and PCL/COL/MH nanofibrous scaffolds (Fig. 6d, f). It was evident that few layers of cells were formed on the $\mathrm{PCL} / \mathrm{COL} / \mathrm{MH}$ matrix surface and secreted their own collagen compound for mineralization on ECM. The presence of collagen helps in proliferation and adhesion of cells which is more suitable for bone tissue regeneration [41]. The higher ADSCs proliferation was observed after 15 days of culture in which the PCL/SF/MH and PCL/COL/MH nanofibrous scaffolds had considerable difference between other scaffolds (Fig. 4). The presence of SF improves the mechanical strength which has a porous nanofibrous structure suitable for cell proliferation and adhesion compared to PCL/COL/MH. The morphology of cells in all the scaffolds was found to be similar, whereas PCL/SF/MH scaffold had a differentiated cuboidal osteoblast structures, for providing a better mechanical
Fig. 9 Quantitative analysis of the mineralization by osteogenic differentiation of ADSCs on TCP, PCL, PCL/SF, PCL/SF/MH, $\mathrm{PCL} / \mathrm{COL}$, and PCL/COL/MH nanofibrous scaffolds. Asterisk indicates significant difference of $P \leq 0.05$

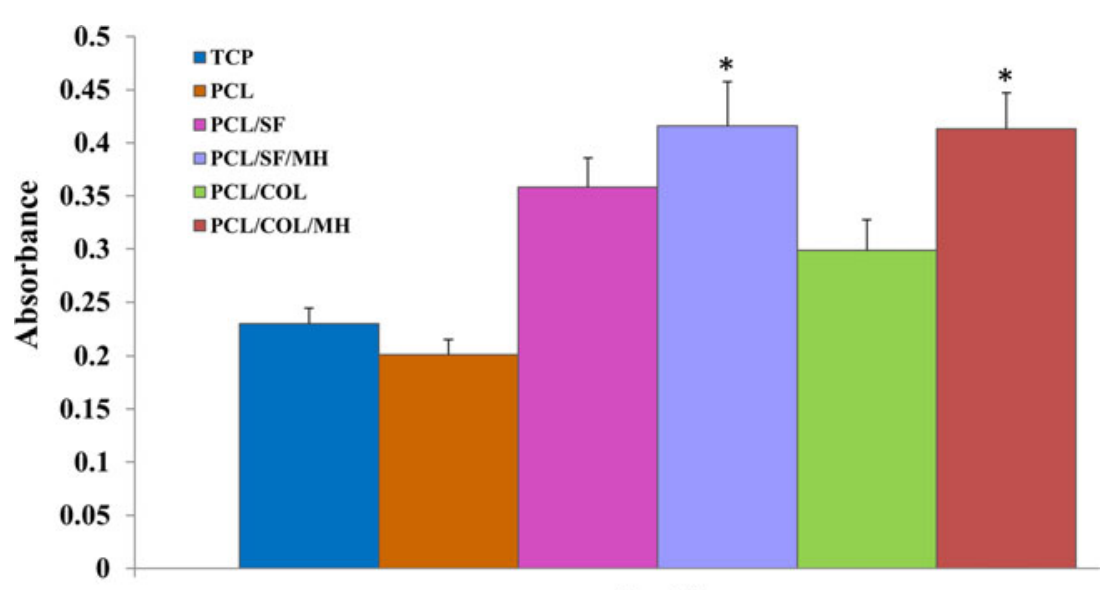

Day 15 
support and higher porosity, which is more favorable for adhesion, interaction, proliferation, migration, and differentiation of cells $[12,24,36]$.

\section{Mineralization of ADSCs}

The bone-forming ability of ADSCs was further analyzed using ALP activity which is the important expression for bone-forming cells [26]. ALP assay is the key factor for bone matrix vesicles due to its contribution in the development of bone minerals and also acts as a main indicator for undeveloped osteoblast activity [1]. It has a major role in initiating the mineralization process and hydrolyses the phosphate esters by increasing the concentration of phosphate and enhances mineralization on ECM [3]. The ALP activity of cells at days 5, 10 , and 15 having a significant increase $(P \leq 0.05)$ in $\mathrm{PCL} / \mathrm{SF} /$
Fig. 10 Confocal microscopy images to confirm the osteogenic differentiation of ADSCs using ADSC specific marker protein CD105 (green) $(a, d, g, j, m, p)$ and osteoblast specific marker protein osteocalcin (red) $(b, e, h$, $k, n, q)$. Merged images showing the dual expression of both CD105 and osteocalcin, characteristic of ADSCs which have undergone osteogenic differentiation $(c, f, i, l, o, r)$ on TCP $(a-c)$, PCL $(d-f)$, PCL/SF $(g-i), \mathrm{PCL} / \mathrm{SF} / \mathrm{MH}(j-l), \mathrm{PCL}$ COL $(m-o)$, and PCL/COL/MH $(p-r)$ with the nuclear staining by DAPI (blue) at $\times 20$ magnification
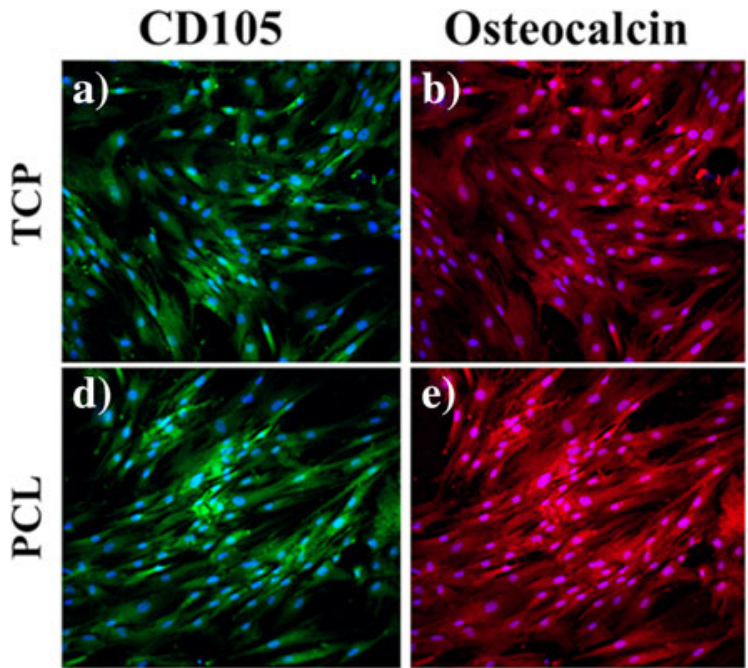

\section{Colocalization}
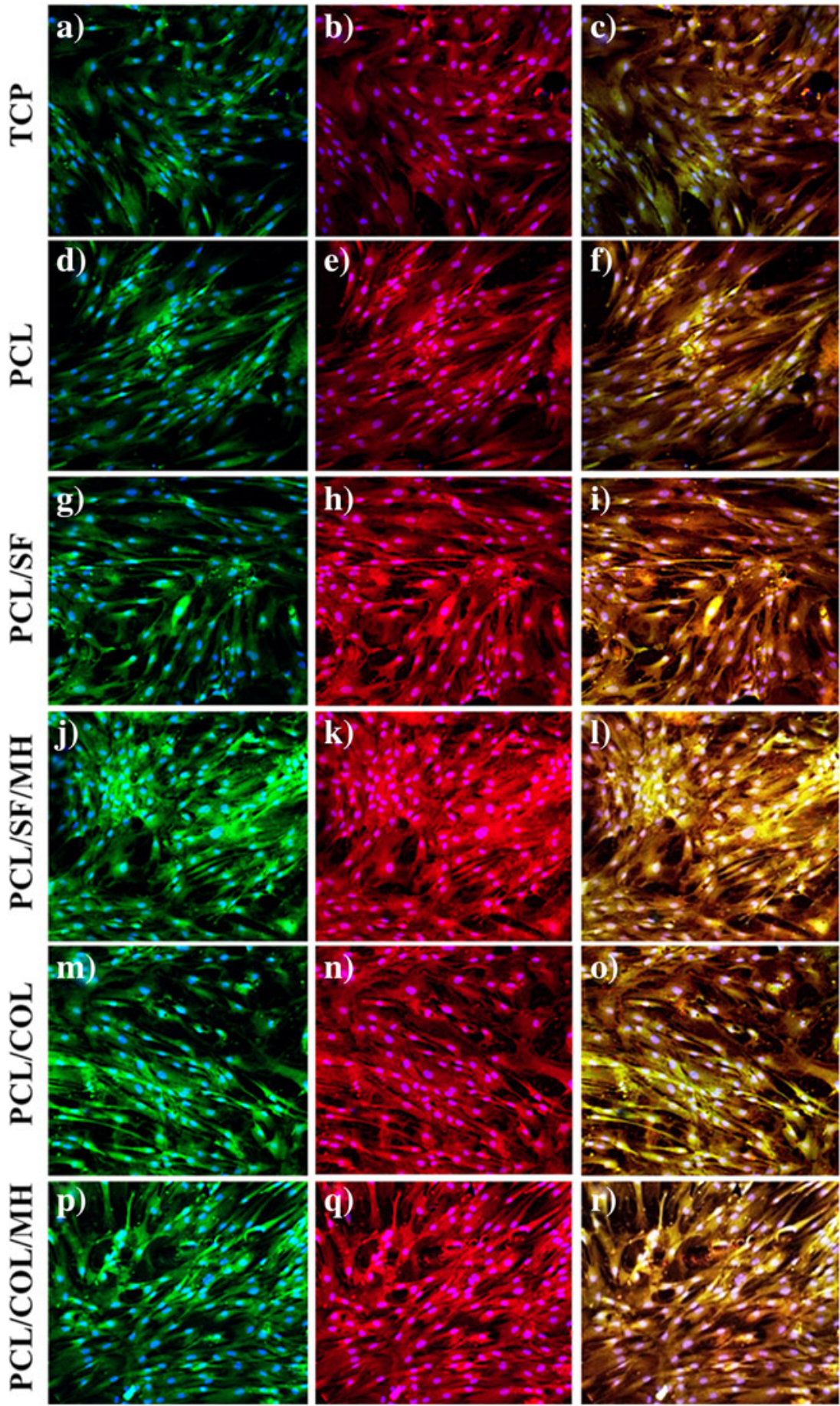
$\mathrm{MH}$ and $\mathrm{PCL} / \mathrm{COL} / \mathrm{MH}$ scaffolds when compared to PCL nanofibers on days 10 and 15 (Fig. 7). ALP activity was increased in the PCL/SF/MH nanocomposite compared to all other biocomposites on 10 and 15 days of cell culture. This is due to the influence of SF which is mechanically strong and stimulates the cells to adhere, proliferate, and finally leads to osteogenesis [23]. Furthermore, the mineralization of cells is a differentiation for mature osteoblasts which can be confirmed by ARS staining by determining the phase change of cells from differentiation to mineralization on ECM. The ARS assay for mineralization was determined qualitatively as shown in Fig. 8a-f. PCL/SF/MH biocomposite had a better mineral deposition compared to PCL nanofibrous scaffolds. The collagenous matrix formation within the surface of scaffold is essential for better bone regeneration process. The significant levels of mineralization attribute a spatial orientation and sheet-like structure formation of cells [36, 14]. Mineralized bone matrix development was quantitatively measured and had a significant $(P \leq 0.05)$ increase of bone mineral deposition in PCL/SF/MH nanofibrous scaffolds when compared with PCL nanofibers cultured on day 15 (Fig. 9). Deposition of bone minerals also contributes in improving the mechanical strength of the bone substrate in bone tissue engineering [6].

\section{Expression of Osteocalcin}

Osteocalcin (OCN) is a bone specific marker protein used for determining the formation of bone minerals, which is a positive step for bone tissue regeneration. The deposition of bone mineral density is highly significant towards the osteocalcin levels for the differentiation of cells. Hence, the presence of higher levels of osteocalcin expression in the nanofibrous scaffolds illustrates the scaffold is suitable for the bone tissue regeneration. The confocal images of ADSCs expressing osteocalcin specific marker protein on TCP, PCL, PCL/SF, $\mathrm{PCL} / \mathrm{SF} / \mathrm{MH}, \mathrm{PCL} / \mathrm{COL}$, and $\mathrm{PCL} / \mathrm{COL} / \mathrm{MH}$ scaffolds were shown in Fig. 10. The obtained results showed an even distribution of cells with a phenotypic expression of higher level of osteocalcin on the PCL/SF/MH nanofibrous scaffolds, which proves to be more suitable for bone tissue regeneration. Figure 10 showed that the ADSCs specific marker protein CD105 expresses in green color. These cells are differentiated into osteogenic lineage showing a red color expressing the $\mathrm{OCN}$ along with CD105 marker protein. On merging the dual expression of both $\mathrm{OCN}$ and $\mathrm{CD} 105$ confirms the ADSCs differentiation into osteogenesis, which is observed more on PCL/SF/MH nanofibrous scaffolds. Therefore, the functionalized biocomposite nanofibrous scaffolds are further attracted for cell adhesion, interaction, proliferation, differentiation, mineralization, and ECM production for bone tissue regeneration [37, 48].

\section{Conclusion}

The electrospun biocomposites nanofibrous scaffolds that mimic the natural ECM should have an enhanced biocompatibility with the composition similar to that of the bone and the bioactive molecules that stimulates the proliferation and secretion of ECM for the diseased site to tissue regeneration. In order to enable the growth, adhesion, proliferation, and differentiation of cells, a mechanically strong, interconnected porous network with high surface to volume ratio of nanofibrous scaffold is necessary to engineer the artificial tissues. Compared to $\mathrm{PCL} / \mathrm{COL} / \mathrm{MH}$ composite, $\mathrm{PCL} / \mathrm{SF} / \mathrm{MH}$ biocomposites nanofibrous scaffold was found to be more suitable for cell adhesion and mechanical stability with high porosity, and provide more space for the exchange of nutrients, metabolic wastes, and oxygen for the regeneration of bone tissues. The present study shows that the PCL scaffold consisting of bioactive macromolecules such as SF provides sufficient mechanical strength and cellular adhesion, whereas $\mathrm{MH}$ acts as an antibiotic that helps the cells to grow without any infection. Therefore, the potentials of PCL/SF/MH scaffolds are more promising for the bone defect treatment as well as in bone tissue regeneration.

Acknowledgments This work was supported by research grants from the Lee Kong Chian School of Medicine, Nanyang Technological University, and Singapore Ministry of Education Academic Research Fund Tier 1 (awarded to Dr Srinivasan Dinesh Kumar, who is the corresponding author of this paper).

\section{References}

1. Anderson HC, Sipe JB, Hessle L, Dhanyamraju R, Atti E, Camacho NP. Impaired calcification around matrix vesicles of growth plate and bone in alkaline phosphatase-deficient mice. Am J Pathol. 2004;164(3):841-7.

2. Anselme K. Osteoblast adhesion on biomaterials. Biomaterials. 2000;21:667-81.

3. Bellows CG, Aubin JE, Heersche JN. Initiation and progression of mineralization of bone nodules formed in vitro: the role of alkaline phosphatase and organic phosphate. Bone Miner. 1991;14(1):2740.

4. Bernier C, Dréno B. Minocycline. Ann Dermatol Venereol. 2001;128(5):627-37.

5. Bhattacharjee P, Kundu B, Naskar D, Kim HW, Bhattacharya D, Maiti TK, et al. Potential of inherent RGD containing silk fibroinpoly (caprolactone) nanofibrous matrix for bone tissue engineering. Cell Tissue Res. 2015. doi:10.1007/s0044101522326.

6. Callan B, Gayathri S, Mostafa E, Eda YA. In situ osteoblast mineralization mediates post-injection mechanical properties of osteoconductive material. J Mech Behav Biomed Mater. 2014;38: 143-53.

7. Chen G, Zhou P, Mei N, Chen X, Shao Z. Silk fibroin modified porous poly(epsilon-caprolactone) scaffold for human fibroblast culture in vitro. J Mater Sci Mater Med. 2004;15:671-7. 
8. Christopher MR, Kyriacos AA. Success rates and immunologic responses of autogenic, allogenic, and xenogenic treatments to repair articular cartilage defects. Tissue Eng B Rev. 2009;15(1):1-15.

9. Cima LG, Vacanti JP, Vacanti C, Ingber D, Mooney D, Langer R. Principles of tissue engineering. Biomech Eng. 1991;113:143-51.

10. Crawford DC, Hallvik SE, Petering RC, Quilici SM, Black LO, Lavigne SA, et al. Post-operative complications following primary ACL reconstruction using allogenic and autogenic soft tissue grafts: increased relative morbidity risk is associated with increased graft diameter. Knee. 2013;20(6):520-5.

11. Fan S, Zang Y, Shao H, Hu X. Electrospun regenerated silk fibroin mats with enhanced mechanical properties. Int J Biol Macromol. 2013;56:83-8.

12. Fatemeh M, Hossein H, Mohammad AS, Chuanbin M, Mingying Y, Mehdi F. Silk as a potential candidate for bone tissue engineering. J Control Release. 2015;215:112-28.

13. Fritsch A, Hellmich C, Dormieux L. Ductile sliding between mineral crystals followed by rupture of collagen crosslinks: experimentally supported micromechanical explanation of bone strength. J Theor Biol. 2009;260(2):230-52.

14. Gandhimathi C, Venugopal JR, Allister TY, Ramakrishna S, Kumar SD. Biomimetic hybrid nanofibrous substrate for mesenchymal stem cell differentiation into osteogenic cell. Mater Sci Eng C. 2015;49:776-85.

15. Gandhimathi C, Venugopal JR, Ravichandran R, Sundarrajan S, Suganya S, Ramakrishna S. Mimicking nanofibrous hybrid bone substitute for mesenchymal stem cells differentiation into osteogenesis. Macromol Biosci. 2013;13:696-706.

16. Giesa T, Arslan M, Pugno NM, Buehler MJ. Nanoconfinement of spider silk fibrils begets superior strength. Extensibility and toughness. Nano Lett. 2011;11:5038-46.

17. Grigoryan AS, Orlov AA, Saburina IN, Zurina IM, Sysoev SD. Dynamics of osteogenesis associated with inoculation of autologous stromal cells from rat adipose tissue (experimental-morphological study). Patol Fiziol Eksp Ter. 2015;59(2):4-11.

18. Guo B, Lei B, Li P, Ma PX. Functionalized scaffolds to enhance tissue regeneration. Regen Biomater. 2015;2(1):47-57.

19. Haslauer CM, Moghe AK, Osborne JA, Gupta BS, Loboa EG. Collagen-PCL sheath-core bicomponent electrospun scaffolds increase osteogenic differentiation and calcium accretion of human adipose-derived stem cells. J Biomater Sci Polym Ed. 2011;22(13): $1695-712$.

20. Hintermann B, Wagener J, Knupp M, Schweizer C, Schaefer JD. Treatment of extended osteochondral lesions of the talus with a free vascularised bone graft from the medial condyle of the femur. Bone Joint J. 2015;97-B(9):1242-9.

21. Hosseini Ravandi SA, Gandhimathi C, Valizadeh M, Ramakrishna S. Application of electrospun natural biopolymer nanofibers. Curr Nanosci. 2013;9:1-11

22. Ito Y, Hasuda H, Kamitakahara M, Ohtsuki C, Tanihara M, Kwon $\mathrm{OH}$. A composite of hydroxyapatite with electrospun biodegradable nanofibers as tissue engineering material. J Biosci Bioeng. 2005;100:43-9.

23. Johanna M, Swati M, Sourabh G, Keita I, Sandra H. Silk fibroin as biomaterial for bone tissue engineering. Acta Biomater. 2015. doi: 10.1016/j.actbio.2015.09.005.

24. Kundu B, Rajkhowa R, Kundu SC, Wang X. Silk fibroin biomaterials for tissue regenerations. Adv Drug Deliv Rev. 2013;65:45770 .

25. Kweon H, Yoo MK, Park IK, Kim TH, Cho CS. A novel degradable polycaprolactone networks for tissue engineering. Biomaterials. 2003;24(5):801-8.

26. Li M, Mondrinos MJ, Chen X, Gandhi MR, Ko FK, Lelkes PI. Coelectrospun poly(lactide-co-glycolide), gelatin, and elastin blends for tissue engineering scaffolds. J Biomed Mater Res A. 2006;79: 963-73.
27. Lin CY, Li LT, Su WT. Study of subcellular dynamics on cellsubstrate interactions by live cell imaging. J Biomed Mater Res A. 2014;102(4):1149-54

28. Liu C, Xia Z, Czernuszka JT. Design and development of three dimensional scaffolds for tissue engineering. Chem Eng Res Des. 2007;85(7):1051-64.

29. Liu TL, Miao JC, Sheng WH, Xie YF, Huang Q, Shan YB, et al. Cytocompatibility of regenerated silk fibroin film: a medical biomaterial applicable to wound healing. J Zhejiang Univ Sci B. 2010;11(1):10-6.

30. $\mathrm{Lu} \mathrm{T}, \mathrm{Li} \mathrm{Y}, \mathrm{Chen} \mathrm{T}$. Techniques for fabrication and construction of three-dimensional scaffolds for tissue engineering. Int J Nanomed. 2013;8(1):337-50.

31. McMahon RE, Wang L, Skoracki R. Development of nanomaterials for bone repair and regeneration. J Biomed Mater Res B. 2013;101:387-97.

32. Ngiam M, Liao S, Patil AJ, Cheng Z, Chan CK, Ramakrishna S. The fabrication of nano-hydroxyapatite on PLGA and PLGA/ collagen nanofibrous composite scaffolds and their effects in osteoblastic behavior for bone tissue engineering. Bone. 2009;45(1):4 16.

33. Nieman GF, Zerler BR. A role for the anti-inflammatory properties of tetracyclines in the prevention of acute lung injury. Curr Med Chem. 2001;8(3):317-25.

34. Pereira IH, Ayres E, Averous L, Schlatter G, Hebraud A, de Paula $\mathrm{AC}$, et al. Differentiation of human adipose-derived stem cells seeded on mineralized electrospun co-axial poly ( $\varepsilon$-caprolactone) (PCL)/ gelatin nanofibers. J Mater Sci Mater Med. 2014;25(4):1137-48.

35. Pountos I, Corscadden D, Emery P, Giannoudis PV. Mesenchymal stem cell tissue engineering: techniques for isolation, expansion and application. Injury. 2007;38(Supp. 4):23-33

36. Promita B, Deboki N, Hae-Won K, Tapas KM, Debasis B, Subhas CK. Non-mulberry silk fibroin grafted PCL nanofibrous scaffold: promising ECM for bone tissue engineering. Eur Polym J. 2015;71: 490-509.

37. Ravichandran R, Venugopal JR, Sundarrajan S, Mukherjee S, Ramakrishna S. Poly(glycerol sebacate)/gelatin core/shell fibrous structure for regeneration of myocardial infarction. Tissue Eng A. 2011;17(9-10):1363-73.

38. Sayin E, Baran ET, Hasirci V. Osteogenic differentiation of adipose derived stem cells on high and low aspect ratio micropatterns. J Biomater Sci Polym Ed. 2015;26(18):1402-24.

39. Sowjanya JA, Singh J, Mohita T, Sarvanan S, Moorthi A, Srinivasan N, et al. Biocomposite scaffolds containing chitosan/ alginate/nano-silica for bone tissue engineering. Colloids Surf B: Biointerfaces. 2013;109:294-300.

40. Vasita R, Katti DS. Nanofibers and their applications in tissue engineering. Int J Nanomed. 2006;1(1):15-30.

41. Venugopal JR, Vadgama P, Sampath Kumar TS, Ramakrishna S. Biocomposite nanofibres and osteoblasts for bone tissue engineering. Nanotechnology. 2007;18:8.

42. Vuong J, Hellmich C. Bone fibrillogenesis and mineralization: quantitative analysis and implications for tissue elasticity. J Theor Biol. 2011;287:115-30

43. Woodfield TB, Miot S, Martin I, van Blitterswijk CA, Riesle J. The regulation of expanded human nasal chondrocyte re-differentiation capacity by substrate composition and gas plasma surface modification. Biomaterials. 2006;27:1043-53.

44. Xu T, Miszuk JM, Zhao Y, Sun H, Fong H. Bone tissue engineering: electrospun polycaprolactone $3 \mathrm{D}$ nanofibrous scaffold with interconnected and hierarchically structured pores for bone tissue engineering. Adv Healthcare Mater. 2015;4(15):2237.

45. Yang Y, Chen X, Ding F, Zhang P, Liu J, Gu X. Biocompatibility evaluation of silk fibroin with peripheral nerve tissues and cells in vitro. Biomaterials. 2007;28:1643-52. 
46. Yukihiko K, Hatsuhiko M. Recent developments of functional scaffolds for craniomaxillofacial bone tissue engineering applications. ScientificWorldJournal. 2013;2013:21863157.

47. Yun YR, Jang JH, Jeon E, Kang W, Lee S, Won JE, et al. Administration of growth factors for bone regeneration. Regen Med. 2012;7(3):369-85.
48. Zhang YZ, Venugopal JR, Huang ZM, Lim CT, Ramakrishna S. Characterization of the surface biocompatibility of the electrospun PCL-collagen nanofibers using fibroblasts. Biomacromolecules. 2005;6(5):2583-9.

49. Zuk PA, Zhu M, Ashjian P. Human adipose tissue is a source of multipotent stem cells. Mol Biol Cell. 2002;13:4279-95. 